\title{
LA MORFOGÉNESIS EVOLUTIVA: UN CAMINO HACIA LA DESMATERIALIZACIÓN
}

\section{EVOLUTIONARY MORPHOGENESIS: A PATH TO THE DEMATERIALIZATION}

Lorenzo Vicente Burgoa: Universidad de Murcia (España) lorenzo.vicbur@um.es

\section{CURRÍCULUM VITAE}

Doctor en Teología por la Universidad de Salamanca en 1955. Profesor de Teoría General del Conocimiento en la Universidad de Murcia (España) y autor de varios libros.

\section{RESUMEN}

La celebración en este año del segundo centenario del nacimiento de Ch. Darwin nos ofrece la ocasión y la acuciante curiosidad por el tema ya a punto de ser clásico, de la evolución biológica. Dejando de lado las teorías y ateniéndonos exclusivamente al hecho evolutivo, como hecho suficientemente comprobado, todavía nos brinda la ocasión y hasta la urgencia de reflexionar una vez más sobre los problemas que plantea, tanto a los científicos, como a los filósofos e incluso a los teólogos.

Nuestra tesis es que la evolución biológica transespecífica, que es un hecho suficientemente comprobado (y aparte de las teorías explicativas), se presenta como un proceso de liberación progresiva de las condiciones de la materia amorfa y como 
un proceso de "emergencia" de formas nuevas y superiores y de acceso a estructuras y funciones cada vez más inmateriales. La flecha de la evolución ¿apunta acaso hacia el Espíritu?

\title{
PALABRAS CLAVE
}

Evolución filogenética - Morfogénesis - Inmaterialidad - Liberación - Comunicación

\begin{abstract}
The celebration this year of the second Centenary of the birth of Charles Darwin offers us the opportunity and the pressing curiosity about the subject and to be a classic of biological evolution. Leaving aside the theories and sticking exclusively to the fact of evolution, as a fact sufficiently proved, yet gives us the opportunity and the urgent need to reflect once more on the problems, both scientists and philosophers and even the theologians. Our thesis is that biological trans-specific evolution, (a fact which is sufficiently apart from the explanatory theories), is presented as a process of gradual release of the terms of the proven of the amorphous material and a process of "emergence" of new and higher forms and access to structures and functions are increasingly intangible. The arrow of the evolution...points to the spirit?
\end{abstract}

\section{KEY WORDS}

Phylogenetic evolution - Morphogenesis - Immateriality - Liberation - Comunication 


\section{TEXTO}

En lo que sigue no pretendo ofrecer algo totalmente nuevo. Es una larga meditación personal (por ello apenas hacemos recurso a otras autoridades) sobre hechos de observación ordinaria y sobre datos de la ciencia, que están al alcance de cualquier estudioso de formación media. Es un ejercicio de penetración y comprensión.

Mi propuesta o tesis es: El hecho de la evolución transespecífica muestra que es un proceso de alejamiento o superación o liberación de la materia hacia formas cada vez más perfectas.

Hablando en general, la llamada "especiación creciente" en las líneas filogenéticas o phylums, no puede tener otra interpretación racional que la de progresiva aparición de formas especificativas, que configuran la estructura del viviente de modo cada vez más adaptado. Estar mejor adaptado significa: ser más capaz de resistir los ataques de predadores o de elementos medioambientales adversos; y además, llevar a cabo operaciones y funciones de manera más precisa, económica y eficaz.

Ahora bien, ello significa, consiguientemente, el predominio de las características de la forma, tal como las hemos descrito anteriormente, sobre las de la materia. Significa la emergencia de formas más perfectas y evolucionadas.

Mas esto que parece bastante razonable así enunciado en general, debe ser comprobado más detenida y minuciosamente en los diversos niveles, reinos y géneros de entes naturales. De ello nos ocupamos a continuación.

Ello puede desplegarse bajo dos sentidos: uno, negativo, como liberación de lo material, tanto estructuralmente, como dinámica o funcionalmente; otro, positivo, como emergencia de formas nuevas. 
La morfogénesis como liberación progresiva y relativa de la materia o de las condiciones de lo material.

Digamos, ante todo, que un proceso de "liberación" implica en su concepto dos aspectos complementarios, algo así como el anverso y el reverso. Es un proceso, ante todo, de independencia respecto de aquello de lo que se libera; y es un proceso de autonomía, de autodeterminación.

La evolución biológica se nos presenta, pues, como proceso de "liberación" bajo ambos aspectos. $\mathrm{Y}$ ello podemos advertirlo tanto en el plano de las estructuras y de las formas, como en el de las funciones.

1) En el plano de las estructuras

En efecto, las configuraciones de los seres vivientes ofrecen ya en su dimensión meramente "física" por así decirlo, una tendencia continuada y creciente de liberación. Ello se muestra p.e. en el proceso de adaptación de las formas al medio (acuático, terrestre, aéreo). Los datos paleontológicos van confirmando cada vez más que las formas primitivas de vida sufren un cambio de adaptación activa. Así se van formando las aletas para la natación, las patas para la carrera, las alas para el vuelo, etc. La pezuña del caballo (equus) se adapta a la estepa, no sólo para resistir su dureza, sino también para dominarla en la carrera; de modo similar el ala del águila, que planea soberanamente por el aire... En los seres que viven en tierra habitualmente, la liberación primero de las patas y quizás simultáneamente de los brazos y de las manos, se muestra como un elevarse físicamente sobre el horizonte y una capacidad para dominar el medio. La posición erecta del homo sapiens sería, hasta el presente, la muestra más clara de esa liberación física, que al aparecer no ha concluido totalmente en su adaptación. Y junto con ello, la liberación del brazo y de los dedos de la mano, que convierten a ésta en el "instrumento de los instrumentos", como decía Aristóteles. Vemos en ello que la especificación de la estructura no 
significa recorte de funciones (como sucede p.e. en las herramientas), sino ampliación libre para funciones múltiples; algunas de las cuales exigen funciones muy refinadas, como p.e. pintar un cuadro, tocar una guitarra o el teclado de un piano o las cuerdas de un violín, etc.

Una similar adaptación activa la contemplamos en las estructuras que tienden, de suyo, a posesionarse del medio físico externo. Así p.e. las que sirven a la digestión y asimilación de alimentos o de aire atmosférico: son organizaciones que han de transformar el medio, por tanto activas, para incorporarlo al propio cuerpo. Los alimentos primero son cortados, masticados, insalivados, digeridos por medio de reactivos químicos de fabricación propia, y finalmente transportados y asimilados por las diversas partes del organismo.

Esa misma liberación, tanto en cuanto independencia como en dominancia sobre el medio aparece en los órganos de captación y de relación. Tales son principalmente el sistema nervioso y los terminales sensibles o sentidos externos. Los ojos, p.e. se han ido formando en un largo proceso de adaptación, que implica no sólo independización, sino también dominación: los conos y los bastones de la película retiniana, que sirven para captar los colores, han de hallarse exentos o independientes de cualquier determinación cromática, pues sino lo veríamos todo del mismo color (como sucede cuando el medio externo entre nuestro ojo y el objeto - p.e. el aire o un cristal - se halla coloreado de forma determinada). Esa independencia nos permite captar los colores, las formas distantes de los objetos, dominar sobre el horizonte y unificarlo en la perspectiva visual. Esa unificación es activa, por parte de nuestra constitución. Algo similar podría decirse de los demás sentidos, p.e. del oído, adaptado a captar cualquier vibración sonora, dentro de unos umbrales selectivos: los umbrales no sólo limitan la capacidad, sino que también la organizan y la determinan. Los sabores ayudan a discriminar y discernir (sentido primitivo de saber, sabiduría) entre las propiedades físico-químicas de los objetos; 
ello nos permite clasificarlos mejor, identificarlos y discernir o juzgar activamente de su nocividad o conveniencia para nosotros.

\section{2) En el plano de las funciones}

Ese mismo sentido de marcha hacia la liberación lo captamos en las funciones emergentes de los vivientes evolucionados. La misma selección natural a nivel radical de mutaciones genéticas, es muy probable que obedezca a tendencias, aspiraciones o necesidades del ser viviente de cara a su realización futura. El que no siempre aparezca esa relación y se atribuyan las mutaciones genéticas al azar puede ser únicamente efecto de nuestra ignorancia, como sucede casi siempre que apelamos al azar. Sin entrar ahora a fondo en esta vieja discusión, diremos que no es ininteligible la presión del medio sobre la organización actual de un viviente, al amparo de tendencias y satisfacción de necesidades de modo más eficaz y de cara al futuro. Esto no sería postular una causa actuando desde el futuro inexistente, concepto difícil de comprender y de aceptar (no vamos a entrar ahora en la discusión de la acción de "causas finales", tan rechazada como ignorada por científicos y por algunos filósofos. En realidad, se parte de una concepción falsa o inepta de finalismo: se supone que el fin ha de ser algo siempre consciente, como si no existieran las tendencias y aspiraciones inconscientes. Y, además, se supone que actúa desde el futuro, que todavía es nada; cuando y según los defensores del finalismo, el fin es siempre algo primario (según Aristóteles, causa causarum); incluso primario respecto del agente actual, que es determinado o movido a obrar de una determinada manera por el objetivo), sino que es una causa presente, el viviente como ser en desarrollo evolutivo, con tendencias y aspiraciones inconscientes a una calidad superior de vida.

Y entendida la selección natural como función que posibilita la continuidad o supervivencia de las formas mejor adaptadas, ello indica, no sólo una manera pasiva 
y como simple resultado casi mecánico; sino que, aparte de obedecer a la ley de una mayor probabilidad de supervivencia, indica sentido activo en cuanto es una lucha por la existencia y la continuidad de las especies. ¿Quién negará este sentido activo de la selección, cuando ello implica frecuentemente incluso la lucha a muerte entre los individuos procreadores?. La misma permanencia asegurada es ya algo activo, en cuanto es perduración, autonomía y victoria sobre los agentes destructivos.

Pero si miramos a otras funciones más específicas de los vivientes evolucionados, vemos que, paralelamente a la liberación de las estructuras, aparece la liberación del comportamiento y de las funciones. Y ello, en estos planos: el motor, el afectivo, el cognitivo, el creativo y el comunicativo.

No es nada nuevo que las funciones motoras implican una liberación ya a nivel de lo físico: la liberación del cuerpo levantado en forma erecta señala el dominio sobre el medio físico, como hemos dicho antes. Y ello quizás más claro en las funciones de vuelo y desplazamiento por el aire. Es una liberación respecto del aquí, del espacio físico concreto; así como respecto de las condiciones de la materia, como la gravedad, el peso específico, la pasividad, la inercia, etc.

En las funciones afectivas, éstas parecen desarrollarse desde unas tendencias ciegas, completamente inconscientes, a unas tendencias cada vez más conscientes y reflejas. Los mamíferos superiores, cercanos al hombre poseen ya una cierta capacidad electiva (elicitiva, decían los antiguos), ya que pueden escoger relativamente sus alimentos (cuando hay abundancia) su pareja (al menos por parte de las hembras...) su hábitat, mejor acondicionado o mejor provisto (para ello los desplazamientos, a veces de miles de kilómetros, como en las aves migratorias, ..); poseen un cierto sentido de previsión, como se ve en la guarda de la caza, de granos, etc (para un estudio comparativo con la liberación evolutiva en los animales superiores, puede 
verse, entre otros: Hauser, M.D.: Mentes salvajes. ¿Qué piensan los animales?. Barcelona, Granica, 2002 (Con abundante bibliografía).

En el hombre, esa capacidad electiva, que arranca de sus tendencias o afectos, se configura como autodeterminación consciente y libre. Si bien, se trata de una libertad objetivamente limitada, pero subjetivamente no está determinada más que por la razón y el juicio, que dictaminan lo conveniente, lo noble, lo moral, lo justo e injusto, etc. La ley positiva, si bien es limitativa de la libertad, es igualmente indicación de la misma, al menos cuando ha sido dictada por el consenso libre de los ciudadanos; y, por otra parte, es normalmente condición de realización efectiva de la libertad humana: donde no existen leyes racionales, se impone la ley del más fuerte que impide la libertad de la mayoría.

En el plano cognitivo hallamos que la adaptación implicada en el hecho cognitivo revela una liberación superior de los seres que llamamos conscientes. Ya en el campo de la sensibilidad externa, con todas sus limitaciones y umbrales, los sentidos de distancia nos permiten captar lo lejano, configuran a escala de perspectiva los tamaños y magnitudes, diversifican mediante la situación espacial, el número y la figura, etc. Es decir, permiten una liberación espacial y situacional respecto de los objetos. Pero en la sensibilidad interna, se presenta una liberación ulterior, mediante la imaginación y la memoria, que someten en cierto modo los acontecimientos en su devenir temporal; y además, los pueden recombinar por encima de sus figuras actuales. La intuición se torna ahora capacidad de captación de relaciones geométricas, figurativas, proyectivas, etc. La sensibilidad interna permite, además, juzgar o estimar aspectos de conveniencia o nocividad, de utilidad o inutilidad, etc.; lo que implica ya liberación importante respecto del aquí y el ahora, así como de esto o aquello, emergencia de lo cualitativo respecto de lo cuantitativo, percepción del medio o instrumento respecto del fin, relevancia de símbolo y significado, etc. Señalemos que la capacidad simbólica, que se ejerce en las imágenes creativas y 
finalmente en los sonidos articulados, es una liberación indudable, como dominio sobre lo extenso y sus relaciones. Se dice que el hombre es "un animal simbólico", capaz de formar y de interpretar los símbolos, capaz de la metáfora: todo esto es algo perceptible, experimentable de alguna manera; mas no puramente material.

Si saltamos ahora a las funciones intelectivas, apreciamos que la liberación llega a límites o cotas, en que lo material parece difuminarse y casi desaparecer. La capacidad de abstracción, sin llegar a la total inmaterialidad positiva, accede a nociones y concepciones que exceden no sólo lo singular material, sino hasta todo lo sensible. Así, p.e. la formación de sistemas científicos o filosóficos, las estructuraciones lógicas, el dominio de las metodologías de investigación, las concepciones cosmológicas globales y las metafísicas (sean o no válidas y objetivas, pero existen en nosotros) indican que la inteligencia humana ha conseguido una liberación y una autonomía superiores. Todavía dependemos de los objetos del mundo, como de materiales con los que trabajar, como un pintor necesita de colores y un compositor musical de sonidos; pero sobre esos materiales se eleva la capacidad comprensiva de la mente, lo mismo que la inspiración del artista, no sujeta ya en sus formas a los elementos materiales. La mente trabaja, pues, de forma independiente y a nivel de concepciones universales, incluso supramateriales.

Los ejemplos anteriores nos llevan a otra forma de liberación: la que posee el hombre en cuanto transformador del medio que le rodea, como artesano, artista o técnico. En ello se ejercita la libertad, no sólo en sentido negativo de independencia respecto de las formas u objetos concretos actuales; sino en sentido positivo de creatividad, de invención de nuevas formas, de transformación del mundo (aunque no sea siempre en beneficio del mundo o del hombre mismo...). Es justamente lo que significa "transformar", cambiar la forma; y si es a una forma mejor o más perfecta, a eso es a lo que llamamos propiamente creación, siquiera sea en un sentido lato: es creación de 
formas más nobles, bellas o útiles, aunque los materiales usados sean algo preexistente.

Finalmente, ese grado de "desmaterialización" y de predominio de lo inmaterial se presenta claramente en la comunicación humana, sobre todo, mediante el lenguaje de sintaxis articulada. El hombre, "animal simbólico" (como dice Casierer), es un ser que inventa y escoge los símbolos, los produce y los descodifica. Pero la esencia del símbolo consiste justamente en ser un instrumento, que apunta a un mundo superior, a un horizonte más allá de lo palpable, visible y material. Y entre todos los simbolos, el lenguaje articulado sintácticamente (formalismo) y capaz de contenidos suprasensibles (intencionalidad semántica), aunque usando materiales físicos (fonemas) expresa en sus formas una nueva dimensión.

Es un hecho que a superiores grados de consciencia corresponden superiores formas de comunicación intersubjetiva (de ello nos hemos ocupado en un trabajo anterior: "La esencia del conocimiento desde la experiencia semántica", en Sapientia (Argentina) 1999 (54)481-498). Por lo que en el lenguaje articulado advertimos claras señales de esa consciencia intelectiva inmaterial. Y ello de múltiples maneras, tanto en el lenguaje declarativo de las ciencias y de la filosofía, que llegan a formulaciones teóricas, matemáticas o metafísicas totalmente liberadas de la materia concreta; como en el lenguaje de creación literaria, que incluye la ironía (o reserva mental), la metáfora, que es como un salto desde una forma sensible a otra espiritual; el simbolismo, la intencionalidad secreta del signo apuntando hacia metas u objetivos superiores; la creatividad como formación de mundos nuevos o meramente posibles; la elevación lírica del poema literario, como creación y como expresión de los perfiles de otras latitudes, que ya exceden el horizonte de lo meramente material. 


\section{Conclusión}

El proceso de emergencia evolutiva se presenta como un proceso de liberación, tanto en sentido negativo (independencia) como en sentido positivo (dominio).

Esa liberación tiene un referente inmediato: el medio físico y material concreto, la materia determinante del aquí (espacio) y del ahora (tiempo). Pero juntamente y en indisoluble unión con ese medio material concreto, se apuntan unas liberaciones sucesivas y progresivas respecto de las condiciones y propiedades de lo material: la pasividad, la multiplicidad, el desorden, la dureza o el peso específico, etc.

Aparece igualmente un proceso de transformación, en cuanto emergencia de nuevas estructuras, nuevas formas más unitivas, más organizadas, mejor adaptadas a las funciones, más liberadas de lo cuantitativo y con predominio creciente de lo cualitativo.

En una palabra, el proceso evolutivo hacia la concienciación superior es un proceso de liberación respecto de lo material en su conjunto, especialmente en sus formas más elementales y groseras. La evolución es un proceso en contra de la materia. Se realiza en la materia, como sujeto inexcusable del proceso y hasta como portadora de los "materiales" de construcción de las estructuras. Pero básicamente es un proceso en contra de las condiciones y limitaciones de la materia física. Hoy día se reconoce casi unánimemente que la misma vida es ya una violación, como se ha dicho, de la tendencia entrópica, propia de lo material.

$\mathrm{Y}$ esto no es una mera especulación ni la abducción de entidades imaginarias o fantasmagóricas. Es algo, como creo haber demostrado (aunque sea brevemente), que cualquiera puede captar en el proceso de la evolución, en el hecho mismo y en su modo de realizarse. Por tanto, un reduccionismo de estos aspectos dejaría fuera, sin 
justificación, un conjunto de datos y de hechos captables por la experiencia objetiva. La objetividad del método científico no consiste en acotar y limitar arbitrariamente los datos de la experiencia; sino en desvelarlos críticamente, no admitiendo lo que no pueda derivarse de dichos datos, pero tampoco menos de lo que en ellos se contiene. 